\title{
Forum
}

\section{Student Motivation in the Latin Classroom}

\author{
Kellie J. Baglio \\ Woodstock High School, Woodstock, Georgia, USA
}

\begin{abstract}
It has been argued that learning a second language requires more self-motivation than other courses (Horwitz, 1995). This article reviews literature on motivation in foreign language classrooms and discusses reasons for the lack of motivation among students in second language classes. Particular attention will be given to addressing reasons why students in Latin classrooms may have less motivation than in other classes. Specifically, intrinsic and extrinsic motivation will be discussed in terms of a Latin classroom. Additionally, this article will discuss what steps can be taken by the teacher to increase motivation and engagement through gameplay, creating a safe space to make mistakes, and turning extrinsic motivation into intrinsic motivation.
\end{abstract}

Keywords: Latin classroom, academic motivation, intrinsic motivation, extrinsic motivation, gamification, language teachers, foreign language education

\section{Introduction}

After 11 years of teaching Latin, I have seen patterns in the success and failure of my students, and the greatest factor determining whether students pass or fail is their motivation to learn the language. I have seen very high-attaining students fail time and again because they have not been willing to try or complete the work. I have struggled with how to motivate my students to learn Latin. If I can figure out how to motivate them to learn the language, success naturally follows. After all, is that not ultimately what all teachers are trying to do - to help their students reach success?

In some cases, there seems to be a stereotypical view of Latin, and students have preconceptions about what to expect in a Latin classroom. Latin is difficult to learn, it is a dead language, it is only for smart kids, and it is only useful if you are planning to be a doctor or a lawyer. These preconceptions linger even after students have been convinced to take the class. Students who do not believe that the language is useful will have less motivation to study and learn it. Additionally, if students view the language as too difficult to learn, they may be afraid of failing and therefore will not try in the first place.

Creating a positive learning environment and building student relationships are vital for a successful education, so these are always my first goals. However, after implementing dynamic lessons and building rapport with my students, some students still refuse to complete work or participate in activities. This leads to students showing poor performance and underdeveloped skills and ultimately failing the class. I have been plagued by the question, what can Latin teachers do to motivate students in their classroom?

Horwitz's (1995) research suggests that intrinsic motivation plays the principal role in students studying second languages. This

Author of correspondence: Kellie J. Baglio, E-mail: Kelliejo230@gmail.com

Cite this article: Baglio, KJ (2022). Student Motivation in the Latin Classroom. Journal of Classics Teaching 23, 75-78. https://doi.org/10.1017/S205863102100074X type of motivation comes from the internal desire to study the language for various reasons. Usually, it is to communicate in that language in social, work, or travel situations, but sometimes it is for enjoyment. The desire to become proficient for communicative reasons intrinsically motivates students to study and master the language (Horwitz, 1995). The study of Latin poses a particular challenge in this regard since the language does not inspire intrinsic motivation in the same way that modern languages do. Students are not studying Latin to be able to order food in a restaurant, get directions, or study abroad in Latin. Students who take Latin are typically extrinsically motivated, i.e. they are pressured by external forces. I survey my students at the beginning of every year and ask why they chose Latin for their language credits. Most often I hear that their parents made them, or they have a goal like higher SAT ${ }^{1}$ scores in mind, or they are going into law or medical school and they view Latin as a means to facilitate their learning there.

Latin teachers are in a specific predicament then, and this is what inspired my research. I wanted to find success stories where teachers have found ways to motivate their students to learn the language. Understanding why students are not motivated can help Latin teachers find ways to change that. Furthermore, understanding how to motivate students in a Latin class will greatly increase their success rates.

\section{Review of Research}

\section{Teacher Impact on Student Motivation}

More than most other factors, the teacher greatly influences the level of motivation within students. This manifests in how motivated the teacher is, what kinds of strategies are used, and what kind of environment the teacher creates within the classroom. Studies have shown that the levels of motivation shown by the teacher can have a positive impact on how motivated the students are (Ahn et al., 2021; Henry and Thorsen, 2019). Henry and Thorsen 
(2019) studied specific language classes and surveyed language students to discover a connection between empathy, emotional connections and classroom motivation. They discovered that the emotional connections between students and teachers created an environment in which students naturally had positive feelings upon arriving in class, and this helped create motivation within the students. Ahn et al.s (2021) study shows that if teachers were given autonomous control over their classrooms and curriculum, they were more naturally motivated. They also suggested through their study that students would have more motivation if their teacher had more autonomous motivation. The adverse of this is also true: if teachers lack autonomous control over their classrooms or they feel controlled by their administrators or district, their students will also lack motivation (Ahn et al., 2021).

In addition to ensuring that teachers are motivated, another important factor in student motivation is their social and emotional security in the classroom. Students must feel safe to successfully learn. This means physically and emotionally safe, including feeling safe to make mistakes. Anxiety among students causes many issues in their success and can prevent students from even attempting tasks out of fear of failure. In our current test-obsessed educational system, it seems to be getting more difficult to motivate students (and teachers) by means other than grades. And if the students are only focused on the grades, failure-avoidance can be a major factor in unmotivating students.

This is particularly important in a second language class where mistakes will happen frequently, sometimes constantly, throughout the learning process. Newland's (2016) study investigated why two specific students were unmotivated in her Latin classroom and concluded that a lack of self-efficacy and failure-avoidance were the two chief contributing factors. The students in her study showed low belief in themselves and their abilities to complete the tasks. This also led to their refusal sometimes to complete any work to avoid failing at the task. Somehow their ideas about their self-worth or natural intelligence were linked to the grades they would receive, so to avoid looking unintelligent through failure at a task, they avoided the task altogether (Newland, 2016). Very often we see this same scenario play out in our classrooms, where students who have low belief in themselves will not attempt the work. The logical conclusion then is to change our methods in assessing students' work and change the focus from grades and performance to rating effort and incremental progress.

Hoath's (2015) case study found that the types of feedback students receive shaped their thinking about trial and error and could even reduce failure-aversion among students. Her research found that process-based feedback (critiquing and commenting on effort and progress), as opposed to performance-based feedback (critiquing and commenting on success or reaching targets), is more successful in motivating students to attempt challenging tasks (Hoath, 2015). Praising a student's ability can negatively impact their motivation because they will link their performance with their inherent talent or intelligence. This is made difficult today, in our grade-obsessed educational system, since 'grades by themselves typically provide little competence-relevant feedback; they merely let students know where they stand relative to others, a focus that can undermine autonomous motivation, especially for the "nonwinners" (Ryan \& Deci, 2020, p. 6). Students may feel that, if they make mistakes, that means they are not smart or capable. Conversely, praising a student's effort can help show the student that there is always room for improvement, and any progress made is a success. Through this process, eventually the student will see the benefits in the effort and the work, instead of the grades, and this is the beginning of fostering intrinsic motivation within our students (Hoath, 2015).

\section{The Importance of Intrinsic Motivation}

As previously mentioned, intrinsic motivation seems to be the biggest contributing factor in student success in a language classroom. It is vitally important then to find ways to foster intrinsic motivation within our students. Studies have shown that feedback that focuses on abilities and performance can actually impede motivation, while feedback that focuses on effort can improve motivation (Bakhtiyarovna, 2021; Hoath, 2015; Lamb, 2017; Lou \& Noels, 2016). Lou and Noels' (2016) research suggested that through changing the types of feedback offered to students, it is possible to change the mindset of language learners to foster more resilience and increase the desire to attempt challenging tasks. They instructed that 'teachers should be mindful of the implicit messages contained in their feedback to students, and be sure to emphasize the importance of effort and learning goals (instead of performance goals), as well as trying different learning strategies in challenging situations' (Lou \& Noels, 2016, p. 30). Receiving appropriate and careful feedback can shape a student's thinking and approach to learning language. Teachers must understand that some learners will react negatively to failures and become unmotivated to learn language. Carefully crafted feedback can change the student's mindset to focus on their process, not their performance.

In addition to changing feedback to change student mindsets, providing compelling and culturally relevant material in the target language is an important factor in motivating students to learn the language. This is one of the pillars of Comprehensible Input, which is gaining traction among Latin language teachers as a viable way to have students engage with a language ${ }^{2}$. The material in any classroom must be compelling for students to care about and be interested in it. I have found that having students read interesting and relevant stories in Latin is a successful way to motivate students and have them engage with the Latin language in a meaningful way. However, there are challenges with that, specifically in Latin textbooks. The most commonly-used textbooks created for Latin education, such as Ecce Romani, The Cambridge Latin Course, and Wheelock's Latin tend to have archaic stories about elite or wealthy Roman families, which are concepts and issues to which our students today may find it difficult to relate. In Ash's (2019) article, she describes the steps she took to successfully 'untextbook' her Latin class in order to intentionally create compelling materials for her students. She describes her success and the increase in motivation among her students through this process, though she cautions against trying to do too much at once, as 'untextbooking' requires time and effort to achieve. I see the value in creating my own materials for my students, because I could create them based on what interests the students have and truly make the material relevant to each student in my class. This is another area where student choice could be incorporated to give students more power over what happens in class. By providing compelling material and offering student choice in the readings, students' interests will increase and it will provide them with some much-needed intrinsic motivation to continue their study of the language.

There may be a lack of natural intrinsic motivation within students to study Latin, but many researchers have documented ways to make their students' motivation more intrinsic. Lamb (2017) contends that teachers can achieve this by satisfying students' needs for autonomy, competence, and relatedness. These are important in all subjects, but especially in language learning, as more interpersonal 
communication occurs in language classes. This is true even in Latin classrooms, where one may find students interacting more with a Latin text than with their peers. Interpersonal communication is still occurring in that setting; therefore, the same motivations will apply for satisfying students' needs for autonomy, competence, and relatedness. Addressing those needs will lead to more positive emotions among the class, and students will have increased internal motivation as a result (Lamb, 2017).

Extrinsic motivation may, in some situations, lead to intrinsic motivation. Ryan and Deci (2020) have completed an immense collection of work on intrinsic motivation. Their studies have showed that some extrinsic motivations can share some of the same qualities as intrinsic motivation, if they are autonomous, meaning that the students have some choice in the matter. By simply allowing student autonomy in the subject, interest and enjoyment will be increased, leading to a sense of value and more intrinsic motivations (Ryan \& Deci, 2020). There are many ways to integrate choice and autonomy in the Latin classroom. Teachers can allow students to show their understanding of reading material through paraphrasing, translating, answering comprehension questions, drawing, or even acting out the stories. Additionally, allowing the students to have some say in what happens in the classroom can give them a sense of ownership and power. A simple way to do this is through informal check-ins with students. Ask the students what is working for them, what they are enjoying, and what they are not enjoying, and then modify your instruction or activities accordingly. My own students have reacted positively to having a voice in our day-to-day operations.

\section{Gamifying to Increase Student Motivation}

Gamification is defined as the process by which game elements like points, tokens, and competition are implemented in a classroom setting. Gamification does not mean simply including review games or vocabulary games in your instruction. It means transforming the instruction, activities, and grades into a game-like structure, including levels, achievements, tokens, and rewards (Hung, 2017). Several studies have shown success in gamifying Latin and Greek classes to help increase student motivation (Evans, 2016; Pavlou, 2020; Pike, 2015). Intrinsically motivated students need less external motivation because they are already inclined to participate. However, students who are more extrinsically motivated may respond favourably to a game setting that includes scores, badges, and similar incentives (Hung, 2017). For some students, there is enjoyment in the game itself, and the competition and excitement of the game can create internal motivation within students who are more extrinsically motivated. Games provide an opportunity for students to compete, earn rewards, fail, and try again in a fun setting. I think all teachers would agree that students typically get excited when they get to play games in class. This is intrinsic motivation in its natural form - students wanting to do something because of enjoyment and a self-driven desire to achieve.

Pavlou (2020) found in her case study that gamifying her lesson on Greek lyric poetry inspired some intrinsic motivation in the beginning in the form of curiosity, challenge, and autonomy, but that extrinsic motivation also existed since the activity would be graded. She concluded that extrinsic motivators could motivate some students to try something new, and that extrinsic motivators, depending on the way they are presented, can increase intrinsic motivation. The goal is to find ways to increase intrinsic motivation within students, especially the ones who do not respond to extrinsic motivators like grades or pressure from parents. Gamifying the classroom helps create a safe space for students to attempt a new skill, make mistakes or fail, receive feedback on their effort, and try again. Rueckert et al. (2020) contend in their study that gamification of instructional material gives students autonomy and a sense of control over what they are learning, which has been shown to positively impact students' intrinsic motivation.

Another positive feature of gamification increasing motivation is the alleviation of stress and anxiety around failure. Failureavoidance has been discussed above as a reason why students will avoid doing any work (Newland, 2016). If mistakes can be reframed in the student's mind, it may change their view on failure from something terrible to simply information on how to improve. Evans (2016) found in her study that game play in her Latin classroom created an optimistic relationship between learning and failure, also interacting with the students' intrinsic motivation.

An important behaviour to foster in students is a growthmindset, encouraging students to not fear mistakes, but learn from them. Language learning is very much trial and error and it can be difficult for students to endure a lot of failure. Most students do not remember being corrected as they grew up for saying things incorrectly, but the corrections, mistakes, and re-corrections happened naturally over time, and through that process, children learned the language. This same process is necessary in a language classroom, but students are more afraid of making mistakes in the classroom setting. Pike's (2015) case study of his own Latin classroom showed that gamifying lessons helped foster a growth mindset within his students, which naturally fostered intrinsic motivation. Since games rely on voluntary participation, they show the students that, with increased effort, they will have greater rewards. Through gamified instruction, mistakes are transformed into learning opportunities, and students value the ability to try again. Gamified instruction creates a safe space for students to learn and allows for more engagement by the students with the material through multiple attempts (Evans, 2016). The link between process-based feedback and gamified lessons is clear in the way it can motivate students to improve their process and get better, rather than focusing on performance and failure.

\section{Discussion}

The power to motivate our students lies within every teacher. We have perhaps the greatest ability to impact student motivation in the classroom. Creating a safe space to make mistakes is a key factor in whether students will be motivated. Students who are afraid of failure will lack the motivation to participate. Gamification of the Latin classroom may offer ways to improve the classroom environment and foster extrinsic and intrinsic motivation. Learning in an environment of 'play' can alleviate the stress of failure, turning mistakes into learning opportunities. The motivations for playing a game - enjoyment, fun, competitiveness, curiosity - are more intrinsic and therefore more effective than other motivations in language learners.

The types of feedback teachers give to their students will greatly impact how students respond and can shape their motivation. Providing valuable, process-based (as opposed to performancebased) feedback can help foster intrinsic motivation within students. Intrinsic motivation is crucial for language learning. Learning Latin poses a particular predicament since it lacks many of the elements that typically intrinsically motivate students. Since Latin teachers must rely heavily on extrinsic motivators, it is important to look at types of motivations that can, in certain situations, translate into intrinsic motivation. Using gameplay and feedback that encourages trial and error will change the mindset of students who previously thought themselves incapable of success. 
The final factor that determines if any of this works is teacher autonomy. Teachers must have their own autonomy to be motivated, which subsequently will motivate students. Constraining and controlling school environments suppresses teacher motivation, leading to apathy and ineffective teaching. Many of the suggestions in this article (gamification, untextbooking, Comprehensible Input) are strategies that teachers will need flexibility and autonomy to test and implement. Teachers themselves need a safe space to try new methods, fail, learn, and try again. Unfortunately, this is not always the case, and many teachers are left without the ability to attempt changes in their classrooms. If the goal is for our students to succeed, and they need to be motivated to succeed, then it is just as important to focus on ways teachers can be supported through their own discoveries and afforded flexibility in how to motivate students.

\section{Conclusion}

I know that motivating students is a struggle for all teachers, but I feel that Latin teachers have largely been left out of the research, and the studies on motivating students in the Latin classroom are few. However, it is just as important for Latin teachers to get involved in the conversation about what we can do to motivate our students. Intrinsic motivation is essential for success, and especially in a Latin classroom; where intrinsic motivation is lacking, it is crucial for Latin teachers to develop ways to foster it through their habits, instruction, and activities. We can do this through positive connections, creating autonomy, gamification, and providing comprehensible, compelling material. Motivation is directly linked to student success, so if we can increase our students' intrinsic motivation to study Latin, then we will naturally increase their success.

\section{Notes}

1 The SAT is an entrance exam used by many colleges and universities in the United States to make admissions decisions by measuring a high school student's college readiness. It is a multiple-choice, pencil-and-paper test created and administered by the College Board (https://collegereadiness.collegeboard.org/ sat).

${ }^{2}$ Krashen, S. (2017); Patrick, R. (2016); Patrick, R. (2019).

\section{References}

Ahn I, Chiu M and Patrick H (2021) Connecting teacher and student motivation: Student-perceived teacher need-supportive practices and student need satisfaction. Contemporary Educational Psychology 64, 1-14.

Ash R (2019) Untextbooking for the CI Latin class: Why and how to begin. Journal of Classics Teaching 20, 65-70.

Bakhtiyarovna R (2021) The role of motivation in learning foreign language. Elementary Education Online 20, 1976-1980.

Evans E (2016) Gamification in a year 10 Latin classroom: Ineffective 'edutainment' or a valid pedagogical tool? Journal of Classics Teaching 17, 1-13.

Henry A and Thorsen C (2019) Weaving webs of connection: Empathy, perspective taking, and students' motivation. Studies in Second Language Learning and Teaching 9, 31-53.

Hoath H (2015) How do different types of goals and feedback affect student motivation in Latin? Journal of Classics Teaching 16, 6-13.

Horwitz E (1995) Student affective reactions and the teaching and learning of foreign languages. International Journal of Educational Research 23, 573-579.

Hung A (2017) A critique and defense of gamification. Journal of Interactive Online Learning 15, 57-72.

Krashen S (2017) The case for Comprehensible Input. Language Magazine 16, 18-22.

Lamb M (2017) The motivational dimension of language teaching. Language Teaching 50, 301-346.

Lou N and Noels K (2016) Changing language mindsets: Implications for goal orientations and responses to failure in and outside the second language classroom. Contemporary Educational Psychology 46, 22-33.

Newland R (2016) Closing the gap: Understanding two year 10 boys' difficulties with comprehension of Latin stories in a mixed comprehensive school. Journal of Classics Teaching 17, 22-30.

Patrick R (2016) Making sense of Comprehensible Input in the Latin classroom. Teaching Classical Languages 6, 108-136.

Patrick R (2019) Comprehensible Input and Krashen's theory. Journal of Classics Teaching 20, 37-44.

Pavlou M (2020) Game-informed assessment for playful learning and student experience (part II). Journal of Classics Teaching 21, 19-30.

Pike M (2015) Gamification in the Latin classroom. Journal of Classics Teaching $16,1-7$.

Rueckert D, Pico K, Kim D and Sanchez XC (2020) Gamifying the foreign language classroom for brain-friendly learning. Foreign Language Annals 53, 686-703.

Ryan R and Deci E (2020) Intrinsic and extrinsic motivation from a selfdetermination theory perspective: Definitions, theory, practices, and future directions. Contemporary Educational Psychology 61. 